\title{
Gender and Racial Differences in Post-Traumatic Stress Disorder and Chronic Fatigue Syndrome: A Twin Study
}

\author{
Osayande Agbonlahor, MD, MPH \\ Department of Health Promotion and Behavioral Sciences, University of Louisville \\ 485 E Gray St $\mid$ Louisville, Kentucky 40202 \\ E-mail: osayande.agbonlahor@loiusville.edu \\ Osasohan Osasuyi, Ph.D. \\ University of Colorado Colorado Springs, 1420 Austin Bluffs Pkwy | Colorado Springs CO 80918
}

\begin{abstract}
History of traumatic exposure in primary care and epidemiological studies suggest increased risks of chronic fatigue syndrome. The objective of this study is to examine the relationship between post-traumatic disorder (PTSD) and chronic fatigue syndrome (CFS) diagnosis among twins. We also examined the impact of sex and birth weight discordance on CFS and PTSD outcomes among twins. A cross-sectional study design was used to analyze the data of twins registered with the Washington State Twin Registry (" $n$ " $=18,398$ ). Sociodemographic characteristics such as age, sex, race, and ethnicity were compared between twin pairs with and without CFS. Generalized estimating equation (GEE) and linear regression was used to measure the correlation between twins' health background. Twins diagnosed with PTSD were 4.1 times more likely to develop CFS compared with those without PTSD (95\% CI: 2.52-6.52) and the odds of female twins being diagnosed with CFS is 2.26 times more than male (95\%CI: 1.74-2.93). Findings of our study identify PTSD, age, being a female twin, separation from a twin before the age of 18, and being victim to traumatic event such as assault and fire as significant predictors of CFS. We did not find sex discordance or birth weight discordance to be significant predictors of CFS. Results of this research requires a holistic approach to treatment and management.
\end{abstract}

Keywords:Chronic Fatigue Syndrome; Post-traumatic stress disorders; Birth weight discordance; Sex discordance; Stress Coping

DOI: $10.7176 / \mathrm{JHMN} / 91-01$

Publication date:July $31^{\text {st }} 2021$

\section{Introduction}

Chronic Fatigue Syndrome (CFS) also known as myalgic encephalomyelitis (ME) is a debilitating long-term illness that is characterized by persistent fatigue not alleviated by rest or induced by exhausting activity, not explained by other conditions, and results in meaningful activity reduction(Collin et al. 2018). Common symptoms of CFS include post-exertional malaise, muscle pain, cognitive dysfunction, and unrefreshing sleep (Yancey and Thomas 2012).

According to an Institute of Medicine (IOM) report in 2015, CFS affects up to an estimated 2.5 million people in the United States, and, generates direct and indirect expenses of approximately 17 billion to 24 billion annually (Komaroff 2019a). The etiology of CFS is currently unknown with the heterogeneous nature of the disease suggesting possible neurologic, immunologic, infectious, and hormonal involvement (Manabendra and Bhattacharyya 2017, Mueller et al. 2019). One hypothesis is that the classic CFS/ME symptoms are because of the release of pro-inflammatory cytokines by microglia in the brain resulting in a state of chronic, low-level neuroinflammation seen in CFS that distinguishes the disorder from other brain illness such as meningitis or encephalitis, and neurodegenerative conditions such as stroke or multiple sclerosis (Komaroff 2017, Mueller 2019).

Studies have found a significant relationship between patients diagnosed with PTSD and CFS (Kato et al. 2006, Lerdal et al. 2010). Our focus on the association between PTSD and CFS is the relationship between the biological and stress coping mechanisms which differ significantly in every individual. The diagnostic criteria for PTSD have been updated in the fifth edition of the American Psychiatric Association's Diagnostic and Statistical Manual of Mental Disorders (DSM-5) with PTSD now belonging to the "Trauma and Stressor-Related Disorders"'(Psychiatry and American Psychiatric 2013, Longo et al. 2017). PTSD is defined by eight diagnostic criteria in the DSM-5 which include; 1) exposure to actual or threatened death, serious injury or sexual violence, 2) presence of one or more intrusive symptoms beginning after traumatic event occurred, 3) persistent avoidance of stimuli associated with traumatic event, 4) negative alterations in cognition and mood associated with traumatic event, 5) marked alterations in arousal and reactivity beginning or worsening after traumatic event, 6) duration of disturbance must be more than one month, 7) clinically significant distress or social and occupational impairment, and 8) the disturbance must not be attributable to substance use or another mental disorder (Psychiatry and American Psychiatric 2013). The estimated prevalence of PTSD in the United States is about 8\% 
in men and $20 \%$ percent in women (Warner et al. 2013) with approximately $80 \%$ of people diagnosed with posttraumatic stress disorder having at least one comorbid psychiatric disorder such as depression, CFS, somatoform disorders and anxiety disorders (Grinage 2003).

Twin studies have been an essential and unique way of distinguishing between genetic and environmental determinants of susceptibility to disease, with special importance in disorders such as CFS where the heritability is known (Schur et al., 2007) but the predictive role of intrauterine environmental factors such as sex and birth weight discordance in the etiology of the disease is obscure. Moreover, other psychological conditions such as depression(Roy-Byrne et al. 2004) and personality disorders (Poeschla et al. 2013) have been shown to have a positive association with CFS diagnosis. It is known that the symptoms of PTSD, like CFS, is partly determined by genetic factors(True, Rice and Eisen 1993) and due to the inherited biological factors associated with PTSD, we believe it is essential and more accurate to examine the predictors of CFS and its association with PTSD in the light of twin studies rather than singletons.

We also worked with twin data because we are interested in assessing the impact of intrauterine environmental variations associated with CFS such as sex and birth weight discordance as predictors of CFS. These two important predictors have been shown in the literature as good predictors of other chronic conditions which can be induced by stress and alterations in cortisol levels such as hypertension(Barker et al. 1990), noninsulin dependent diabetes (Poulsen et al. 1997), asthma(Ryan et al.), respiratory distress syndrome(Perelman et al. 1986) and childhood problem behavior (Os et al. 2001). Hence, it is crucial to identify the role of early predictors in life such as sex discordance and birth weight discordance to show the importance of intra-uterine impact on diagnosis of poor health outcomes later in life.

However, literature has little to offer about the association between sex discordance and CFS, although the impact of the male hormone on female adverse health outcome has been studied extensively (Somboonporn, Bell and Davis 2005, Elraiyah et al. 2014). Birth weight discordance (BWD) among twins may result from a combination of intrinsic factors (placenta sharing and cord insertion abnormalities resulting in the unequal provision of nutrients to the fetuses) and extrinsic factors (maternal complications) that affect fetal growth rate(Jahanfar and Lim 2017). Birth weight discordance between twins has been broadly linked with poor adult health outcomes as a proxy for environmental conditions during prenatal development(Tan et al. 2014, Poulsen et al. 1997). Twin pairs' birth weight discordance and sex discordance provide an essential model for assessing the environmental variation between twins (Tan et al. 2014). Hence, the objectives of the twin study are to:

1. Determine the possible significant relationship that may exist between twins diagnosed with PTSD and CFS as an outcome

2. We are also interested in assessing the impact of sex and birth weight discordance on the outcomes of CFS.

\section{Method \\ 2.1 Sample}

This is a cross-sectional study and all twins enrolled in the study were participants in the Washington State Twin Registry, a community-based sample of twins derived from the driver's license of the Washington State Department of Licensing. To avoid duplicate licenses and identification numbers, the Department of Licensing ask every new applicant if they are twins or not. The Washington State twin registry receives the list of twins and invites each member of the pair to join the registry and complete a health survey. The survey contains sociodemographic characteristics, physician-diagnosed health conditions, habits, health care use and standardized psychiatric measures and measures of physical health.

\subsection{Primary Measures}

We analyzed twin data from the Washington State Twin Registry (" $n$ " = 18,398), and the study was approved by the Washington State University Institutional Review Board. Informed Consent was obtained from all participants upon inclusion in the registry. Variables collected include sociodemographic characteristics of twins with twins in this study reporting their gender, age, ethnicity (Hispanic/Latino) and race (White, Black/African American, Asian, Native Hawaiian/Pacific Islander, Alaska Native/American Indian, other). Other questions asked about the type of trauma (fire, sexual assault, combat-related, other) experienced, zygosity, country of birth and age when first apart from the twin. Age was examined as a continuous variable. A self-reported physician diagnosis of PTSD and CFS by twins in the study was also recorded. CFS is defined as lifetime chronic fatigue syndrome that was determined by a self-report of an official physician diagnosis. Twins were asked, "Has a doctor or medical professional ever diagnosed you with chronic fatigue syndrome".

PTSD is defined as post-traumatic stress disorder that was also determined by a self-report of an official physician diagnosis. Twins were asked, "Has a doctor or medical professional ever diagnosed you with posttraumatic stress disorder". BWD is defined as birth weight discordance and was determined by a self-report from the twins enrolled in the study. Twins were asked, "Who weighed more at birth, you or your twin" and 
responses were recorded. Zygosity was determined by asking twins, "When you were children, were you and your twin as alike as two peas in a pod? ", and responses were recorded.

To determine sex discordance and sex-pairing, twins were asked the sex of the other twin. Same-sex twins (Male-Male or Female-Female twin pairs) were defined as sex concordant twins while Male-Female sex pairs were defined as sex-discordant twins. In cases where mismatches were made in individual questions, questions were asked again to clarify and recorded. These responses recorded where analyzed and we performed descriptive and bivariate analysis by comparing groups of twins with and without a physician diagnosis of CFS.

\subsection{Statistical Analysis}

Data were analyzed using the IBM SPSS Statistics for Windows, version 25.0. We checked the data for errors, duplicate entries, and retrievable missing data. We checked the data twice by analyzing frequencies to ensure the validity of data. In cases where the error was found, verification was made by referring to the questionnaires. Using a coding system, making backups, and keeping the data in a safe place guaranteed the security of data. Descriptive analysis was done using an independent " $T$ " test and Mann-Whitney " $U$ " tests for quantitative variables when necessary. Chi-square and Fisher's Exact tests were also used to determine the relationships between variables. A " $p$ " value of less than 0.05 was considered significant.

The Generalized estimating equation model (GEE) was performed to ascertain the various risk factors for CFS outcomes, taking into consideration the shared environmental effects and genetics between monozygotic and dizygotic twin pairs. The primary effects of interest in the model were the relationship between PTSD and CFS. Other variables such as age, sex, type of traumatic event, and age when twins first moved apart were included in the final multivariate GEE model in addition to PTSD and CFS as they improved the model fit and precision.

\section{Results}

\subsection{Descriptive Analysis}

Table 1 presents the results of the descriptive statistics. The sample included 18,398 twins with ages ranging from 18-97 (Mean $\pm(\mathrm{SD})=41.65 \pm(18.59)$ ). The study population was predominantly female ("n" $=11,259$, $61.2 \%$ ), white ("n" $=16,969,92.2 \%$ ), monozygotic (" $n "=9,756,53 \%)$, sex concordant ("n" $=14,382,78 \%$ ) and were born in the United States (" $n$ " $=5,262,28.6 \%$ ) (Table 1). An estimated $13.9 \%$ of twins reported physical or sexual assault, which was the most common type of traumatic event experienced by twins. The lifetime prevalence of self-reported physician diagnosis of CFS and PTSD was $1.9 \%$ and $4.6 \%$, respectively (Table 1 ). $29.8 \%$ reported having persistent thoughts, images, or dreams after a stressful or traumatic event (Table 1).

Table 1. Sociodemographic and health characteristics of twins from the Washington State Twin Registry ("n" =18,398).

\begin{tabular}{|l|l|l|}
\hline Variables & Mean $( \pm$ SD) & Minimum-Maximum \\
\hline Age & $41.65( \pm 18.59)$ & $18-97$ \\
\hline \multicolumn{2}{|l|}{} \\
\hline Age when twins first moved apart & Frequency & Percentage \\
\hline Still together & 894 & 4.9 \\
\hline Before 18 years of age & 1189 & 11.7 \\
\hline After 18 years of age & 8069 & 79.5 \\
\hline Sex & \multicolumn{2}{|l|}{} \\
\hline Male & 7139 & 38.8 \\
\hline Female & 11259 & 61.2 \\
\hline Sex pair & \multicolumn{2}{|l|}{} \\
\hline MM & 5132 & 27.9 \\
\hline FF & 9250 & 50.3 \\
\hline MF & 4016 & 21.8 \\
\hline Race & \multicolumn{2}{|l|}{} \\
\hline Hispanic & 694 & 3.8 \\
\hline White & 16969 & 92.2 \\
\hline Black or African American & 468 & 2.5 \\
\hline Asian & 626 & 3.4 \\
\hline American Indian or Alaska Native & 351 & 1.9 \\
\hline Native Hawaiian or Pacific Islander & 140 & 0.8 \\
\hline Other & 390 & 2.1 \\
\hline Country Born & 5262 \\
\hline United States & 28.6 \\
\hline \multicolumn{2}{|l|}{} \\
\hline
\end{tabular}




\begin{tabular}{|l|l|l|}
\hline Canada & 58 & 0.4 \\
\hline European & 82 & 0.78 \\
\hline Asian & 26 & 0.36 \\
\hline Sex concordance & 14382 & 0.78 \\
\hline Sex concordant & 4016 & 0.21 \\
\hline Sex discordant & \multicolumn{2}{l|}{} \\
\hline Weighed more at birth. & 2163 & 11.8 \\
\hline You & 2271 & 12.3 \\
\hline Your twin & 330 & 1.8 \\
\hline Same & \multicolumn{2}{l|}{} \\
\hline Zygosity & 8642 & 47 \\
\hline Dizygotic twins & 9756 & 53 \\
\hline Monozygotic twins & \multicolumn{2}{l|}{} \\
\hline Traumatic event & 2558 & 13.9 \\
\hline Assault & 517 & 2.8 \\
\hline Combat & 1159 & 6.3 \\
\hline Fire & 3001 & 16.3 \\
\hline Other & 5475 & 29.8 \\
\hline Recurrent thoughts/images/dreams after traumatic event & 829 & 4.6 \\
\hline PTSD & 345 & 1.9 \\
\hline CFS & \multicolumn{1}{|l|}{} \\
\hline
\end{tabular}

*Some Variables do not add up to the population and percentage total due to missing values.

\subsection{Bivariate Analysis.}

Twins were divided into two groups (with [" $n$ " $=345]$ and without [" $n "=18053]$ CFS). We examined the relationships between twins with PTSD and CFS. Sex, sex pairing and zygosity were statistically significantly associated ("p" $=0.01$, "p" $=0.01$ and " $p "=0.04$ respectively) (Table 2). Assault, exposure to fire, trauma from other traumatic exposures (excluding assault, fire, and combat), and recurrent thoughts/dreams after traumatic event were all shown to be statistically significant with CFS ("p" $=0.01$ for all). Previous combat exposure, however, was shown to not be significantly associated with CFS diagnosis ("p" $=0.21$ ) (Table 2). No statistical significance was found between sex discordance and CFS (" $p "=0.19$ ). (Table 2).

We also found noteworthy that none of the 138 twins who identified as Native Hawaiian/ Pacific Islanders enrolled in this study reported a diagnosis of CFS. Twins who were first moved apart from their co-twin before the age of 18 were also found to have a significant association with CFS ("p" $=0.01$ ) (Table 2). An independent sample "T" test found a statistically significant association between age and CFS ("p" $=0.01$ ).

3.3. Generalized estimating equation (GEE) Analysis.

Twins diagnosed with PTSD were 4.24 times more likely to develop CFS compared with those without PTSD (95\% CI: 3.38-5.33). After adjusting for age and sociodemographic characteristics, twins with PTSD were 4.10 times more likely to develop CFS (95\% CI: 2.52-6.52). (Table 3). Female twins who reported a physician diagnosis of PTSD were more than 2 times more likely than males to be diagnosed with CFS (95\%CI: 1.74-2.93). (Table 3). In the unadjusted analysis, exposure to traumatic events such as fire and assault were found to be significant in diagnosis of CFS. Twins with exposure to fire were more than twice likely to develop CFS [AOR: $2.23,(95 \% \mathrm{CI}): 1.59-3.11)]$ compared to those without traumatic exposure to fire, and twins with a history of sexual and/or physical assault were more than three times likely to be diagnosed with CFS [AOR: $3.20,(95 \%$ CI): 2.50-4.10)] (Table 3). Sex discordance was not shown to have a statistically significant impact on the outcome of CFS ("p" $=0.30$ ) (Table 3) 
Table 2. Comparison between twins with and without CFS(n=18,398)

\begin{tabular}{|c|c|c|c|}
\hline & $\begin{array}{l}\text { CFS + } \\
" N "=345\end{array}$ & $\begin{array}{l}\text { CFS - } \\
" N "=18053\end{array}$ & "P" value \\
\hline & $\operatorname{Mean}( \pm S D)$ & $\operatorname{Mean}( \pm S D)$ & \\
\hline Age & $49.1( \pm 16.6)$ & $41.4( \pm 18.6)$ & 0.01 \\
\hline & "N" (\%) & "N" (\%) & "P" value \\
\hline $\begin{array}{l}\text { Sex } \\
\text { Male } \\
\text { Female } \\
\end{array}$ & $\begin{array}{l}76(1.1) \\
269(2.4)\end{array}$ & $\begin{array}{l}6868(98.9) \\
10732(97.6)\end{array}$ & 0.01 \\
\hline $\begin{array}{l}\text { Sex concordance } \\
\text { Sex concordant } \\
\text { Sex discordant } \\
\end{array}$ & $\begin{array}{l}262(1.9) \\
83(2.1) \\
\end{array}$ & $\begin{array}{l}13773(98.1) \\
3827(97.9)\end{array}$ & 0.30 \\
\hline $\begin{array}{l}\text { Sex Pairing } \\
\text { Male-Male twin pair } \\
\text { Female-Female twin } \\
\text { Male-Female twin } \\
\end{array}$ & $\begin{array}{l}44(0.9) \\
218(2.4) \\
83(2.1)\end{array}$ & $\begin{array}{l}4949(99.1) \\
8824(97.6) \\
3827(97.9) \\
\end{array}$ & 0.01 \\
\hline $\begin{array}{l}\text { Which twin weighed more at birth } \\
\text { You } \\
\text { Your co-twin } \\
\text { The same }\end{array}$ & $\begin{array}{l}25(1.2) \\
43(2.0) \\
7(2.2)\end{array}$ & $\begin{array}{l}2050(98.8) \\
2124(98.0) \\
311(97.8) \\
\end{array}$ & 0.10 \\
\hline $\begin{array}{l}\text { Zygosity } \\
\text { Dizygotic twins } \\
\text { Monozygotic twins } \\
\end{array}$ & $\begin{array}{l}181(2.1) \\
164(1.7)\end{array}$ & $\begin{array}{l}8239(97.9) \\
9361(98.3) \\
\end{array}$ & 0.04 \\
\hline Hispanic or Latino & $14(2.1)$ & $665(97.9)$ & 0.78 \\
\hline $\begin{array}{l}\text { Race } \\
\text { Asian } \\
\text { Black or African American } \\
\text { White } \\
\text { American Indian or Alaska Native } \\
\text { Others } \\
\text { Native Hawaiian or Pacific islander }\end{array}$ & $\begin{array}{l}3(0.5) \\
12(2.6) \\
325(2.0) \\
10(2.9) \\
7(1.9) \\
0\end{array}$ & $\begin{array}{l}611(99.5) \\
447(97.4) \\
16225(98.0) \\
337(97.1) \\
378(98.1) \\
138(100.0) \\
\end{array}$ & $\begin{array}{l}0.01 \\
0.28 \\
0.20 \\
0.19 \\
0.92 \\
0.10 \\
\end{array}$ \\
\hline $\begin{array}{l}\text { Age when twins first moved apart. } \\
\text { Still together } \\
\text { Before age } 18 \\
18 \text { and older }\end{array}$ & $\begin{array}{l}1(0.1) \\
41(4.7) \\
117(1.2)\end{array}$ & $\begin{array}{l}856(99.9) \\
1115(95.3) \\
7707(98.8)\end{array}$ & 0.01 \\
\hline PTSD & $79(9.8)$ & $731(90.2)$ & 0.01 \\
\hline $\begin{array}{l}\text { Traumatic event experienced. } \\
\text { Assault } \\
\text { Combat } \\
\text { Fire } \\
\text { Other } \\
\text { Recurrent thoughts/dreams/images after } \\
\text { traumatic event }\end{array}$ & $\begin{array}{l}107(4.3) \\
13(2.6) \\
42(3.7) \\
113(3.9) \\
217(4.1)\end{array}$ & $\begin{array}{l}2377(95.7) \\
490(97.4) \\
1084(96.3) \\
2811(96.1) \\
5126(95.9)\end{array}$ & $\begin{array}{l}0.01 \\
0.21 \\
0.01 \\
0.01 \\
0.01\end{array}$ \\
\hline
\end{tabular}

*Fisher's Exact Test. No Native Hawaiian or Pacific Islander reported CFS diagnosis.

\subsection{Sex Pairing}

Sex pairing was significantly associated with CFS in the unadjusted analysis, with Female-Female twin pairs 2.42 times more likely to develop chronic fatigue syndrome when compared with Male-Female twin pairs (95\%CI:1.66-3.52) (Table 3). However, including the sex discordance variable in the multivariate GEE analysis, did not show any significant role for sex pairing in the outcomes of CFS, as such sex pairing was excluded from the final model to maximize the precision of the model study. 
Table 3: Unadjusted and Adjusted risk ratios for the association between CFS, PTSD, sociodemographic characteristics, and exposure to specific traumatic event.

\begin{tabular}{|c|c|c|}
\hline Variable & OR (95\% CI) & AOR (95\% CI) \\
\hline PTSD & $4.38(3.14-6.13)$ & $3.23(1.83-5.69)$ \\
\hline Age & $0.98(0.97-0.99)$ & \\
\hline $\begin{array}{l}\text { Traumatic Event } \\
\text { Assault } \\
\text { Fire } \\
\text { Other }\end{array}$ & $\begin{array}{l}3.20(2.50-4.10) \\
2.23(1.59-3.11) \\
2.88(2.25-3.68)\end{array}$ & $\begin{array}{l}1.26(0.71-2.22) \\
2.04(1.00-4.17) \\
1.22(0.70-2.13) \\
\end{array}$ \\
\hline $\begin{array}{l}\text { Age when twins first moved apart } \\
\text { Still together } \\
\text { Before age } 18 \\
18 \text { and older } \\
\end{array}$ & $\begin{array}{c}1 \\
1.86(1.65-8.10) \\
0.42(0.29-0.61) \\
\end{array}$ & $\begin{array}{c}1 \\
0.44(0.27-0.76) \\
0.12(0.10-0.61) \\
\end{array}$ \\
\hline $\begin{array}{l}\text { Sex } \\
\text { Female }\end{array}$ & $2.43(1.59-3.69)$ & $2.93(1.37-6.26)$ \\
\hline $\begin{array}{l}\text { Ethnicity } \\
\text { Hispanic }\end{array}$ & $1.17(0.52-2.67)$ & \\
\hline $\begin{array}{l}\text { Race } \\
\text { Asian } \\
\text { Black or African American } \\
\text { American Indian or Alaska Native } \\
\text { White } \\
\text { Other }\end{array}$ & $\begin{array}{l}0.25(0.08-0.76) \\
1.37(0.77-2.45) \\
1.55(0.82-2.92) \\
1.36(0.84-2.18) \\
0.98(0.46-2.08)\end{array}$ & \\
\hline Sex discordance & $1.08(0.71-1.62)$ & \\
\hline $\begin{array}{l}\text { Sex Pairing } \\
\text { *Female-Female twin pair } \\
\text { *Male-Male twin pair }\end{array}$ & $\begin{array}{l}3.08(1.59-5.95) \\
0.83(0.54-1.26)\end{array}$ & \\
\hline $\begin{array}{l}\text { Which twin weighed more at birth } \\
\text { You } \\
\text { Your twin }\end{array}$ & $\begin{array}{l}1.43(0.54-3.76) \\
0.94(0.36-2.40)\end{array}$ & \\
\hline
\end{tabular}

Dependent variable: CFS; AOR adjusted for sociodemographic characteristics, traumatic event, and age. *Malefemale twin pair controlled for sex-pairing only.

\section{Discussion}

The first objective of this study was to examine the relationship between PTSD and CFS diagnosis among twins. This hypothesis was supported, as our findings from a large, diverse twin registry which included twins born in multiple countries worldwide, showed a strong association between self-reported physician diagnosed PTSD and a lifetime diagnosis of CFS among twins. These findings are replicated in some studies (Kato et al. 2006, Dansie et al. 2012), but not others (Roy-Byrne et al. 2004). Literature also emphasizes on the relationship between exposure to traumatic life events and a lifetime diagnosis of CFS (Lutgendorf et al. 1995, Salit 1997, Theorell et al. 1999), with childhood trauma (Fisher and Chalder 2003, Kato et al. 2006, Heim et al. 2009) and physical and sexual assaults (Van Houdenhove et al. 2001) shown to have significantly increased risks among patients diagnosed with CFS compared to the normal population. Our results showed a significant association between traumatic exposure to assault (physical or sexual) and self-reported physician diagnosis of CFS, lending support to the previous research (Van Houdenhove et al. 2001) done in this area ("p" $=0.037$ ).

Some studies have produced conflicting results, where no significant difference was found between sexual assault in adolescence or adults and CFS when compared to the normal population(Taylor and Jason 2002). Former studies were based on singleton data and therefore lack information about common genetic or environmental background which has been shown to be crucial for CFS etiology. A total of 248 patients with CFS as defined by the CDC criteria and 248 controls were recruited in a study done in Australia to determine the association between CFS and the corticosteroid-binding globulin(CBG) gene polymorphism(Torpy et al. 2004). Results suggested homozygosity for the serine allele of the CBG gene may predispose to CFS(" $p$ " =0.03) (Torpy et al. 2004). Due to the contributions of genes seen in both CFS and PTSD manifestations, we find it important to study the relationship between CFS and PTSD in the light of twin data where the role of genes and shared intrauterine environment is taken into consideration.

The second objective of this study was to assess the impact of sex discordance and birth weight discordance on CFS and PTSD outcomes. Although our bivariate analysis showed that sex-pairing was associated with both 
PTSD and CFS, our regression analysis did not verify this finding, however, this suggests more research should be done on sex-pairing and sex discordance in twins and its role in CFS diagnosis and management. Previous literature among singleton and twins has shown the association between sex and CFS with females more prone to CFS than males (Reeves et al. 2007, Dansie et al. 2012). However, to the best of our knowledge, no study to date has been done on sex discordance. Previous literature has also highlighted the role of birth weight discordance(BWD) on other chronic health conditions(Poulsen et al. 1997) however, to the best of our knowledge, no study to date has been done on its association with CFS as an outcome. The results of our study are unique as we focused on the relationship between sex discordance and BWD among twins, a unique contribution to the field of medical research. We encourage future research to focus on the possible relationship between these two variables and CFS outcome.

Recent advances in the understanding of the pathophysiology of CFS shows that the central and autonomic nervous system plays a crucial role in CFS diagnosis and management. (Komaroff 2019b). There is a growing belief that CFS is a disorder of adaptation and high emotional reactivity (Wearden and Appleby 1996, Eglinton and Chung 2011), as individuals with inherently negative adaptive cognitions such as the feeling of hopelessness after a traumatic event have a higher likelihood of developing CFS, highlighting the importance of stress coping mechanism in individuals diagnosed with CFS (Eglinton and Chung 2011). Previous studies done have also shown a positive association between CFS diagnosis and emotional morbidity (Lawrie and Pelosi 1994). Although our study did not measure emotional response to the physical or sexual assault, our findings of statistical significance between twins with a report of exposure to physical or sexual assault and diagnosis of CFS give some relevance to the hypothesis that CFS is a disorder of adaptation initiated by environmental insults, leading to a negative cognitive response. These suggest that the mechanism of CFS may be autonomic in nature with the disorder mediated by the central nervous system (Craig and Kakumanu 2002a).

Reports of hypercortisolism in patients with CFS has generated much interest recently, with this phenomenon believed to occur after a prolonged period of hyperactivity of the hypothalamic-pituitaryadrenal(HPA) axis due to chronic stress (which may be as a result of a traumatic event such as sexual assault, war or fire exposure) (Craig and Kakumanu 2002b, Fries et al. 2005, Torres-Harding et al. 2008). Hypercortisolism in an individual can lead to the disinhibition of central autonomic stress responses in the brain, resulting in symptoms of fatigue, cognitive impairment and chronic pain (Heim, Ehlert and Hellhammer 2000). A study done using position emission tomography(PET) analysis to compare 18 patients diagnosed with CFS and 6 healthy controls, showed significant altered frontal cortisol metabolism in patients diagnosed with CFS compared to those that were not ("p" $=0.01$ ) (Tirelli et al. 1998), highlighting the possible diagnostic role screening for cortisol levels in patients suspected for CFS can play in the understanding and effective management of the disorder.

Another common hypothesis is that CFS causes chronic, low-level neuroinflammation (Komaroff 2017), with many of its symptoms possibly as a result of the release of pro-inflammatory cytokines by microglia in the brain (Mueller et al. 2019). Several studies done using lumbar punctures to analyze cerebrospinal fluid of CFS patients have supported this hypothesis, with elevated levels of pro-inflammatory cytokines and decreased levels of anti-inflammatory cytokines found in CFS/ME patients (Peterson et al. 2015, Hornig et al. 2017).

We also found in our study that female twins diagnosed with PTSD where more than twice more likely to develop CFS, which is consistent with multiple studies finding females more prone to disorders such as CFS and PTSD following exposure to a traumatic event (Reeves et al. 2007, Dansie et al. 2012, Steven Betts et al. 2013). We postulate that female twins diagnosed with PTSD may be more likely to be diagnosed with CFS compared to males due to a general reluctance from males to seek medical help (Corney 1990, Husaini, Moore and Cain 1994) and the failure of females to respond to a stressful event adequately due to an enhanced stress response.

\section{Limitations and Strengths}

There are several limitations to this study. Firstly, we have relied on retrospective self-report of a physician diagnosis of both CFS and PTSD which is subject to information bias. It is therefore difficult to draw a concise conclusion about the impact of intrauterine environment on CFS given the self-report question regarding birth weight, rather than an actual measurement. Clinical interviews and medical assessments, although unfeasible in the current study because of its large-scale nature may have better-identified symptoms of both disorders and aid in diagnosis confirmation or refutation. Both disorders are often mis-reported due to the stigma associated with diagnosis, and CFS may be misdiagnosed or underdiagnosed due to the vagueness of symptoms. These may have influenced results by overestimating but more likely underestimating the association seen between PTSD and CFS in twins. However, the large-scale nature of this study increases the precision of findings, therefore controlling for any significant bias from self-reports. Secondly, the twin data from the Washington State Twin Registry are not fully representative of twins in the society and so the generalizability of results may be limited. Thirdly, due to the cross-sectional design of the study, we were unable to determine if psychopathology preceded PTSD, mediated between PTSD and CFS, or occurred secondary to CFS in cases of PTSD, therefore posing the 
problem of temporality.

This study is based on a community-based registry of twins with a high-quality data (Afari et al. 2006). One of the strengths of this study is the large size of the data sample compared to the previously published papers, which increases the estimate of high precision of the results of an association between PTSD and CFS. The use of twin pairs as subjects in our study is a strength as it allows for the control of genetic and shared environmental effects from rearing, confounders not seen in singleton study and in determining if a quasi-causal relationship exists.

\section{Conclusion}

In conclusion, despite the limitations of this study, the large size of the data study estimates a high precision for the clarification of the study between twins diagnosed with PTSD and CFS. The findings of our study warrant a holistic approach from future researchers as the search for more effective treatment and understanding of the etiology of CFS continues. A great deal more is known today than 35 years ago about the possible etiology and pathophysiology of CFS, with research done showing a difference in biological and hormonal measurements in CFS individuals from healthy control individuals (Komaroff 2019b), as such, physicians should be encouraged to employ more comprehensive management involving exercise, optimal diet, sleep hygiene and SSRI in combination with cognitive-behavioral therapy for patients diagnosed with CFS(Craig and Kakumanu 2002b). Physicians should also focus efforts on adequately managing stressful events in patients with this disorder and effective education on coping strategies.

\section{Financial Support}

There was no funding for this study.

\section{Conflict of Interest}

The authors have no conflict of interest to report.

Declaration of interest: None.

This research is based on the MPH thesis of the corresponding author from Central Michigan University.

\section{References}

American Psychiatric Association, 2013. Diagnostic and statistical manual of mental disorders: DSM-5. American Psychiatric Publishing, Arlington, VA.

Afari, N., C. Noonan, J. Goldberg \& K. Edwards (2006) University of Washington Twin Registry: Construction and Characteristics of a Community-Based Twin Registry. Twin Research and Human Genetics, 1023-1029.

Barker, D. J., A. R. Bull, C. Osmond \& S. J. Simmonds (1990) Fetal and placental size and risk of hypertension in adult life. BMJ (Clinical research ed.), 301, 259.

Collin, S. M., J. Heron, S. Nikolaus, H. Knoop \& E. Crawley (2018) Chronic fatigue syndrome (CFS/ME) symptom-based phenotypes and 1-year treatment outcomes in two clinical cohorts of adult patients in the UK and The Netherlands. Journal of Psychosomatic Research, 104, 29-34.

Corney, R. H. (1990) Sex differences in general practice attendance and help seeking for minor illness. Journal of Psychosomatic Research, 34, 525-534.

Craig, T. \& S. Kakumanu (2002a) Chronic Fatigue Syndrome: Evaluation and Treatment. American Family Physician, 1083-1091.

--- (2002b) Chronic Fatigue Syndrome: Evaluation and Treatment. American Family Physician, 65, 1083

Dansie, E. J., P. Heppner, H. Furberg, J. Goldberg, D. Buchwald \& N. Afari (2012) The Comorbidity of SelfReported Chronic Fatigue Syndrome, Post-Traumatic Stress Disorder, and Traumatic Symptoms. Psychosomatics, 53, 250-257.

Eglinton, R. \& M. C. Chung (2011) The relationship between posttraumatic stress disorder,illness cognition,defense styles,fatigue severity and psychological well-being in chronic fatigue syndrome. Psychiatry Research, 245-252.

Elraiyah, B. T., M. M. Sonbol, H. Z. Wang, H. T. Khairalseed, H. N. Asi, H. C. Undavalli, H. M. Nabhan, H. B. Firwana, H. O. Altayar, H. L. Prokop, H. V. Montori \& H. M. Murad (2014) The Benefits and Harms of Systemic Testosterone Therapy in Postmenopausal Women With Normal Adrenal Function: A Systematic Review and Meta-analysis. The Journal of Clinical Endocrinology \& Metabolism, 99, 3543-3550.

Fisher, L. \& T. Chalder (2003) Childhood experiences of illness and parenting in adults with Chronic Fatigue Syndrome. Journal of Psychosomatic Research, 54, 439-443.

Fries, E., J. Hesse, J. Hellhammer \& D. H. Hellhammer (2005) A new view on hypocortisolism. Psychoneuroendocrinology, 30, 1010-1016. 
Grinage, B. D. (2003) Diagnosis and management of post-traumatic stress disorder. American Family Physician, 68, 2401-2408.

Heim, C., U. Ehlert \& D. H. Hellhammer (2000) The potential role of hypocortisolism in the pathophysiology of stress-related bodily disorders. Psychoneuroendocrinology, 25, 1-35.

Heim, C., U. M. Nater, E. Maloney, R. Boneva, J. F. Jones \& W. C. Reeves (2009) Childhood Trauma and Risk for Chronic Fatigue Syndrome: Association With Neuroendocrine Dysfunction. Archives of General Psychiatry, 66, 72-80.

Hornig, M., C. G. Gottschalk, M. L. Eddy, X. Che, J. E. Ukaigwe, D. L. Peterson \& W. I. Lipkin (2017) Immune network analysis of cerebrospinal fluid in myalgic encephalomyelitis/chronic fatigue syndrome with atypical and classical presentations. Translational Psychiatry, 7, e1080.

Husaini, B. A., S. T. Moore \& V. A. Cain (1994) Psychiatric Symptoms and Help-Seeking Behavior Among the Elderly: An Analysis of Racial and Gender Differences. Journal of Gerontological Social Work, 21, 177196.

Jahanfar, S. \& K. Lim (2017) Adverse maternal outcomes and birth weight discordance in twin gestation: British Columbia, Canadian data. International Journal of Women's Health, 871-878.

Kato, K., P. F. Sullivan, B. Evengård \& N. L. Pedersen (2006) Premorbid Predictors of Chronic Fatigue. Archives of General Psychiatry, 63, 1267-1272.

Komaroff, A. L. (2017) Inflammation correlates with symptoms in chronic fatigue syndrome.(COMMENTARY). Proceedings of the National Academy of Sciences of the United States, 114, 8914.

--- (2019a) Advances in Understanding the Pathophysiology of Chronic Fatigue Syndrome. The Journal of American Medical Association, 499-500.

--- (2019b) Advances in Understanding the Pathophysiology of Chronic Fatigue Syndrome.(Report). JAMA, The Journal of the American Medical Association, 322, 499.

Lawrie, S. M. \& A. J. Pelosi (1994) Chronic fatigue syndrome: prevalence and outcome. BMJ : British Medical Journal, 308, 732 .

Lerdal, A., K. A. Lee, B. Rokne, Ø. Knudsen Jr, A. K. Wahl \& A. A. Dahl (2010) A population-based study of associations between current posttraumatic stress symptoms and current fatigue. Journal of Traumatic Stress, 23, 606-614.

Longo, D. L., A. Shalev, I. Liberzon \& C. Marmar (2017) Post-Traumatic Stress Disorder. The New England Journal of Medicine, 376, 2459-2469.

Lutgendorf, S. K., M. H. Antoni, G. Ironson, M. A. Fletcher, F. Penedo, A. Baum, N. Schneiderman \& N. Klimas (1995) Physical Symptoms of Chronic Fatigue Syndrome Are Exacerbated By the Stress of Hurricane Andrew. Psychosomatic Medicine, 57, 310-323.

Manabendra, N. \& P. C. Bhattacharyya (2017) CHRONIC FATIGUE SYNDROME. Journal of Evidence Based Medicine and Healthcare, 4, 5213-5217.

Mueller, C., J. C. Lin, S. Sheriff, A. A. Maudsley \& J. W. Younger (2019) Evidence of widespread metabolite abnormalities in Myalgic encephalomyelitis/chronic fatigue syndrome: assessment with whole-brain magnetic resonance spectroscopy. Brain imaging and behavior.

Os, J. v., M. Wichers, M. Danckaerts, S. Van Gestel, C. Derom \& R. Vlietinck (2001) A prospective twin study of birth weight discordance and child problem behavior. Biological Psychiatry, 50, 593-599.

Perelman, R. H., M. Palta, R. Kirby \& P. M. Farrell (1986) Discordance between male and female deaths due to the respiratory distress syndrome. Pediatrics, 78, 238.

Peterson, D., E. W. Brenu, G. Gottschalk, S. Ramos, T. Nguyen, D. Staines \& S. Marshall-Gradisnik (2015) Cytokines in the Cerebrospinal Fluids of Patients with Chronic Fatigue Syndrome/Myalgic Encephalomyelitis. Mediators of Inflammation, 2015.

Poeschla, B., E. Strachan, E. Dansie, D. Buchwald \& N. Afari (2013) Chronic Fatigue and Personality: A Twin Study of Causal Pathways and Shared Liabilities. Annals of Behavioral Medicine, 45, 289-298.

Poulsen, P., A. A. Vaag, K. O. Kyvik, D. Møller Jensen \& H. Beck-Nielsen (1997) Low birth weight is associated with NIDDM in discordant monozygotic and dizygotic twin pairs. Diabetologia, 40, 439.

Psychiatry, o. \& A. American Psychiatric. 2013. Diagnostic and statistical manual of mental disorders : DSM-5. In DSM-5.

Reeves, W. C., J. F. Jones, E. Maloney, C. Heim, D. C. Hoaglin, R. S. Boneva, M. Morrissey \& R. Devlin (2007) Prevalence of chronic fatigue syndrome in metropolitan, urban, and rural Georgia.(Research)(Report). Population Health Metrics, 5, 5.

Roy-Byrne, P., W. R. Smith, J. Goldberg, N. Afari \& D. Buchwald (2004) Post-traumatic stress disorder among patients with chronic pain and chronic fatigue. Psychological Medicine, 34, 363-368.

Ryan, A., G. Raquel, H. John, L. R. Caroline \& T. Kate Sex discordance in asthma and wheeze prevalence in two longitudinal cohorts. PLoS ONE, 12, e0176293.

Salit, I. E. (1997) Precipitating factors for the chronic fatigue syndrome. Journal of Psychiatric Research, 31, 
59-65.

Somboonporn, W., R. J. Bell \& S. R. Davis (2005) Testosterone for peri and postmenopausal women. Cochrane Database of Systematic Reviews, Issue 4.

Steven Betts, K., G. M. Williams, J. M. Najman \& R. Alati (2013) Exploring the Female Specific Risk to Partial and Full PTSD Following Physical Assault. Journal of Traumatic Stress, 26, 86-93.

Tan, Q., M. Frost, B. T. Heijmans, J. von Bornemann Hjelmborg, E. W. Tobi, K. Christensen \& L. Christiansen (2014) Epigenetic signature of birth weight discordance in adult twins.(Research article)(Report). BMC Genomics, 15, 1062.

Taylor, R. R. \& L. A. Jason (2002) Chronic fatigue, abuse-related traumatization, and psychiatric disorders in a community-based sample. Social Science \& Medicine, 55, 247-256.

Theorell, T., V. Blomkvist, G. Lindh \& B. Evengard (1999) Critical life events, infections, and symptoms during the year preceding chronic fatigue syndrome (CFS): an examination of CFS patients and subjects with a nonspecific life crisis. Psychosomatic Medicine, 61, 304-310.

Tirelli, U., F. Chierichetti, M. Tavio, C. Simonelli, G. Bianchin, P. Zanco \& G. Ferlin (1998) Brain positron emission tomography (PET) in chronic fatigue syndrome: preliminary data. The American Journal of Medicine, 105, 54S-58S.

Torpy, D. J., A. W. Bachmann, M. Gartside, J. E. Grice, J. M. Harris, P. Clifton, S. Easteal, R. V. Jackson \& J. A. Whitworth (2004) Association between chronic fatigue syndrome and the corticosteroid-binding globulin gene ALA SER polymorphism. Endocrine Research, 417-429.

Torres-Harding, S., M. Sorenson, L. Jason, K. Maher, M. A. Fletcher, N. Reynolds \& M. Brown (2008) The associations between basal salivary cortisol and illness symptomatology in chronic fatigue syndrome. Journal of applied biobehavioral research, 13, 157.

True, W. R., J. Rice \& S. A. Eisen (1993) A Twin Study of Genetic and Environmental Contributions to Liability for Posttraumatic Stress Symptoms. Archives of General Psychiatry, 257-264.

Van Houdenhove, B., E. Neerinckx, R. Lysens, H. Vertommen, L. Van Houdenhove, P. Onghena, R. Westhovens \& M.-B. D'hooghe (2001) Victimization in Chronic Fatigue Syndrome and Fibromyalgia in Tertiary Care: A Controlled Study on Prevalence and Characteristics. Psychosomatics, 42, 21-28.

Warner, C. H., C. M. Warner, G. N. Appenzeller \& C. W. Hoge (2013) Identifying and managing posttraumatic stress disorder. American family physician, 88, 827.

Wearden, A. J. \& L. Appleby (1996) Research on cognitive complaints and cognitive functioning in patients with chronic fatigue syndrome (CFS): What conclusions can we draw? Journal of Psychosomatic Research, 41, 197-211.

Yancey, J. R. \& S. M. Thomas (2012) Chronic fatigue syndrome: diagnosis and treatment.(Disease/Disorder overview). American Family Physician, 86, 741. 